\title{
CEREBROVASCULAR ACCIDENT AND ITS ASSOCIATION WITH DURATION OF HYPERTENSION AND DIABETES MELLITUS
}

\author{
Fahad Bin Haris ${ }^{1}$, Padmaja Hari², Faseel P3
}

1Second Year MBBS Student, MES Medical College Hospital, Perinthalmanna.

${ }^{2}$ Associate Professor, Department of Physiology, MES Medical College Hospital, Perinthalmanna.

${ }^{3}$ Resident Medical Officer, Department of Neuromedicine, MES Medical College Hospital, Perinthalmanna.

\begin{tabular}{l}
\hline ABSTRACT \\
BACKGROUND \\
Cerebrovascular Accident (CVA) or Stroke is encountered everyday in clinical practices. Almost all patients with CVA have \\
antecedents of hypertension or diabetes. Identifying a risk factor for the development of CVA is of much importance in preventing \\
the incidence of stroke. Proper management of hypertension and diabetes reduce the risk of CVA.
\end{tabular}

\section{MATERIALS AND METHODS}

A descriptive study was conducted among 150 CVA patients admitted to the Department of General Medicine and Neurology, MES Medical College Hospital, Malappuram and age and sex matched people without CVA were selected from the community.

\section{RESULTS}

It is found that out of 150 patients considered $80 \%$ were hypertensive, $54 \%$ had history of type 2 diabetes mellitus and $45.33 \%$ had history of both hypertension and diabetes. From this study, it was found that the duration of hypertension $(\mathrm{p}<0.001)$ and duration of diabetes mellitus ( $p<0.001$ ) holds a significant association in development of CVA.

\section{CONCLUSION}

It is very clear that hypertension and diabetes mellitus are related to CVA. The longer the duration of these conditions, the higher the risk for CVA. So it is advisable to take necessary steps in controlling hypertension and diabetes, and to make them aware of the early signs and symptoms of CVA.

\section{KEYWORDS}

CVA- Cerebrovascular Accident, Hypertension, Diabetes Mellitus.

HOW TO CITE THIS ARTICLE: Haris FB, Hari P, Faseel P. Cerebrovascular accident and its association with duration of hypertension and diabetes mellitus. J. Evolution Med. Dent. Sci. 2018;7(02):199-202, DOI: 10.14260/jemds/2018/44

\section{BACKGROUND}

According to WHO, Cerebrovascular accident is the second most dreaded disease after myocardial infarction in the world. It is the third most common cause of death in highincome countries after cancer and ischaemic heart disease. It is the most common cause of several physical disability.[1] It is also the most prevalent neurologic disorder in terms of both morbidity and mortality. Stroke is the most common clinical manifestation of cerebrovascular disease. Stroke, a highly prevalent condition exacts a substantial societal toll in the form of the "Dreaded-D's," which are the leading cause of chronic disability, the second leading cause of dementia and the fourth leading cause of death in the United States (US).[2]

Before the CT era, two population-based studies on CVA were undertaken in India. The first study was a populationbased study conducted in Vellore, Tamilnadu, South India covering 258,576 people during the late 1960 s and early 1970 s. $^{[3]}$ This study revealed an incidence of $13 / 100,000$ person-years and a point prevalence of $42 / 100,000$. The second study was conducted at Rohtak, Haryana, North India

'Financial or Other Competing Interest': None.

Submission 02-08-2017, Peer Review 20-12-2017,

Acceptance 27-12-2017, Published 08-01-2018.

Corresponding Author:

Fahad Bin Haris,

Pulimoottil, Ambady Parambu,

Valiyamaram Ward,

Alappuzha-1, Kerala.

E-mail: fahad.cancerresearch@yahoo.com

DOI: $10.14260 /$ jemds $/ 2018 / 44$
(1971 - 1974). Eighty-two cases of stroke were recorded yielding an annual incidence of 33/100,000 person-years. Unfortunately, no incidence study was reported from India over the next 2 decades. ${ }^{[4]}$

Identifying a risk factor for the development of CVA is of much importance in preventing the incidence of stroke. There is need for a study that could depict the hypertensive status and its association to CVA among the local population. About $33 \%$ urban and $25 \%$ rural Indians are hypertensive. Of these, $25 \%$ rural and $42 \%$ urban Indians are aware of their hypertensive status. Only $25 \%$ rural and $38 \%$ of urban Indians are being treated for hypertension. One-tenth of rural and one-fifth of urban Indian hypertensive population have their BP under control.[5]

Similar is the picture of diabetes mellitus. According to Wild et al,[6] the prevalence of diabetes is predicted to double globally from 171 million in 2000 to 366 million in 2030 with a maximum increase in India. Worryingly, diabetes is now being shown to be associated with a spectrum of complications and to be occurring at a relatively younger age within the country. The level of morbidity and mortality due to diabetes and its potential complications are enormous and pose significant healthcare burdens on both families and society. There is now the demand for urgent research and intervention at regional and national levels - to try to mitigate the potentially catastrophic increase in diabetes that is predicted for the upcoming years. ${ }^{[7]}$

Being this the scenario prevalent in the Indian population, there finds the relevance of this study aimed to find whether any relation exists between the duration of hypertension, 
diabetes mellitus and the onset of cerebrovascular accident in our community.

\section{MATERIALS AND METHODS}

This study was undertaken after obtaining ethical and scientific approval from the Institutional Ethics and Scientific committee of MES Medical College, Perinthalmanna. Study design approved was of a descriptive study. Using the formula $4 \mathrm{pq} / \mathrm{d}^{2}$, the prevalence of hypertension among CVA patients as $69 \%$ according to a study done by Zeenat Qureshi Stroke Research Centre ${ }^{8}$ and $10 \%$ absolute error the sample was calculated.

The study was conducted among patients admitted with CVA to the Department of General Medicine and to the Department of Neuromedicine, MES Medical College Hospital. Patient's details and history were collected as per a predesigned proforma. Different methods were adopted in collecting the requisite data. Data was collected directly from patients and their bystanders by means of history taking and necessary clinical examinations. In some cases case, files were collected on demand from the Medical Records Department and those recorded data were made use of. In some other cases, discharge summary of patients with cerebrovascular accident were collected and the required information were sorted out.

After collecting the data few information like hypertensive status, diabetic history, duration of being hypertensive or diabetic, age and gender of the patient, etc. were emphasised and separately highlighted. This helped to prioritise the vital information and a measure to compare data collected. The criteria used for data collection focuses mainly on cerebrovascular accident, hypertension and diabetes mellitus. The diagnostic criteria used for cerebrovascular accident ${ }^{[9]}$ was-

- Unilateral or bilateral motor impairment (including discoordination).

- Unilateral or bilateral sensory impairment.

- Aphesis/ dysphasic (non-fluent speech).

- Hemianopia (half-sided impairment of visual fields).

- Diplopia.

- Forced gaze (conjugate deviation).

- Dysphagia of acute onset.

- Apraxia of acute onset.

- Ataxia of acute onset.

- Perception deficit of acute onset.

The Diagnostic Criteria used for Hypertension[10] wasAccording to the Joint National Committee 7 (JNC 7), hypertension is defined as physician office systolic BP level of $\geq 140 \mathrm{mmHg}$ and diastolic BP of $\geq 90 \mathrm{mmHg}$. The JNC 7 defines normal BP as a systolic BP $<120 \mathrm{mmHg}$ and diastolic $\mathrm{BP}<80 \mathrm{mmHg}$. The gray area between systolic BP of 120-139 $\mathrm{mmHg}$ and diastolic BP of $80-89 \mathrm{mmHg}$ is defined as "prehypertension."

\section{The Diagnostic Criteria used for Diabetes Mellitus[11]} was-

1. HbA1c $\geq 6.5 \%$. The test should be performed in a laboratory using a method that is NGSP certified and standardised to the DCCT assay.*
2. $F P G \geq 126 \mathrm{mg} / \mathrm{dL}(7.0 \mathrm{mmol} / \mathrm{L})$. Fasting is defined as no caloric intake for at least 8 hours.*

OR

3. 2-h plasma glucose $\geq 200 \mathrm{mg} / \mathrm{dL}$ (11.1 mmol/L) during an OGTT. The test should be performed as described by the World Health Organisation using a glucose load containing the equivalent of $75 \mathrm{~g}$ anhydrous glucose dissolved in water.*

\section{OR}

4. In a patient with classic symptoms of hyperglycaemia or hyperglycaemic crisis, a random plasma glucose $\geq 200$ $\mathrm{mg} / \mathrm{dL}$ (11.1 mmol/L).

*In the absence of unequivocal hyperglycaemia, criteria 1-3 should be confirmed by repeat testing.

These are the core ideas by which the data requisite of the study was fulfilled.

Data collection was extended by including the control population. 150 case controls were considered in analysing the data and in finding association between CVA and duration of hypertension and diabetes mellitus. Control population data was collected successfully by conducting a medical camp in a Panchayat (Vangad) near by the hospital. Control population for the study was sorted out according to the age and gender match criterion. Minimum cut-off age limit was 30 years. Collected data was entered in Microsoft Excel and analysed using IBM-compatible Statistical Package for Social Sciences (SPSS) version 20.0. Statistical analyses was done using the Chi-square test: $\mathrm{p}$ value of $<0.05$ was considered significant and at $<0.001$ was considered highly significant and a ' $p$ ' value $>0.05$ was considered not significant.

\section{RESULTS}

This study considered a total of 150 patients, all 150 patients were diagnosed with Cerebrovascular accident and was admitted to the MES Medical College Hospital.

In these 150 cases 84 patients were male, that is $56 \%$ of the total and only $44 \%$ that is 66 patients were females. This is depicted in Graph No. 1.

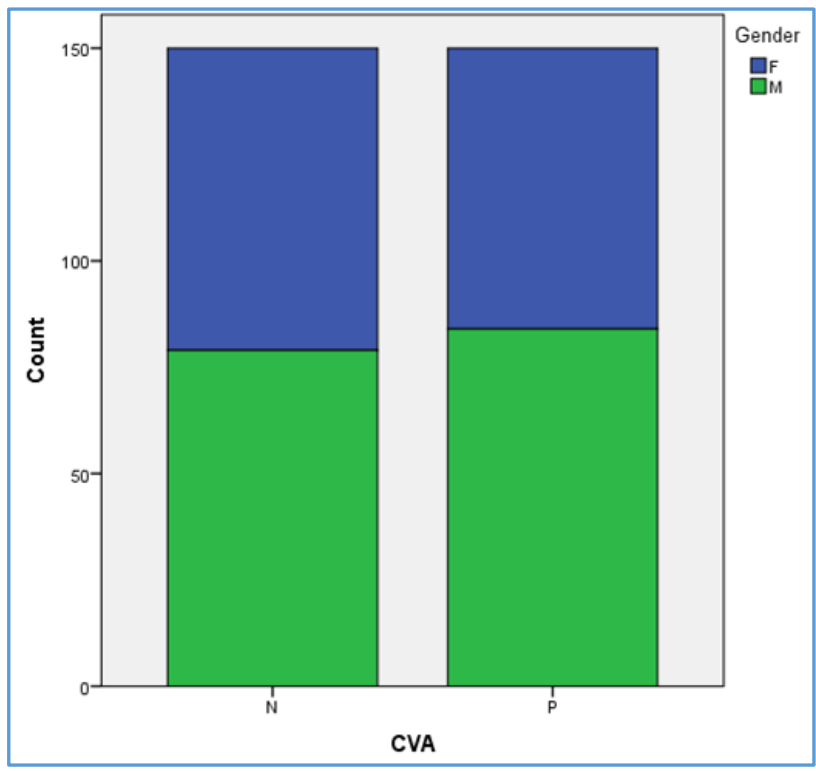

Graph 1. Gender Distribution of Case and Control Population

N- (CVA Negative), P- (CVA Positive) 


\begin{tabular}{|c|c|c|c|}
\hline & Case (n=150) & $\begin{array}{c}\text { Control } \\
(\mathbf{n = 1 5 0 )}\end{array}$ & $\begin{array}{c}\text { Total } \\
(\mathbf{n = 3 0 0})\end{array}$ \\
\hline Range & $31-88$ & $30-84$ & $30-88$ \\
\hline $\begin{array}{c}\text { Mean } \\
\text { (Standard } \\
\text { Deviation) }\end{array}$ & $\begin{array}{c}62.39 \\
(10.599)\end{array}$ & $\begin{array}{c}59.25 \\
(12.614)\end{array}$ & $\begin{array}{c}60.82 \\
(11.736)\end{array}$ \\
\hline \multicolumn{3}{|c|}{ Table 1. Descriptive Statistics of Age Distribution among } \\
Case and Control Populations \\
\hline
\end{tabular}

Considering the age distribution of these patients, it is found that the youngest patient was of 31 years old and it was a male patient. Then youngest female patient was of 32 years old. Graph No. 2 shows this age distribution of all 150 patients.

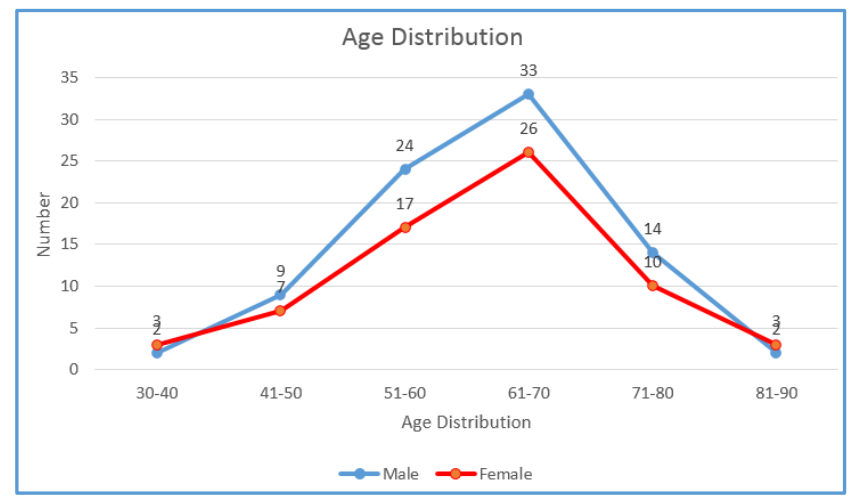

Graph 2. Age Distribution of Male and Female CVA Patients

Table number 2a shows the duration or time period of CVA patients and control populations, since they have been diagnosed to have hypertension. Table $2 \mathrm{~b}$ shows the duration or time period since they have been diagnosed to have diabetes mellitus. Only few of them were aware of their previous hypertensive or diabetic history. Among these few, only a very few patients were on regular medication. To be exact only 36 hypertensive patients and 27 diabetic patients among the case population were aware of their disease history, whereas among the control population much more were aware of their disease history and were on regular medication. Previous studies also support this picture prevalent among the Indian population. ${ }^{[5]}$

This study facilitated in drawing a clear picture regarding Cerebrovascular accident and its association with duration of hypertension and diabetes mellitus. The study result is depicted in Table No. 2a and $2 \mathrm{~b}$ and it was analysed using the IBM SPSS version 20.0 using the Chi-square test. From this analysis, it was found that the duration of hypertension and CVA holds a highly significant association $(p=0.000001)$. It is proven that duration of diabetes mellitus also has a significant association with the incidence of CVA $(\mathrm{p}=0.000025)$.

\begin{tabular}{|c|c|c|}
\hline \multirow{2}{*}{ Duration } & \multicolumn{2}{|c|}{ Diabetes } \\
\cline { 2 - 3 } & CVA & Controls \\
\hline$<1$ Years & 1 & 4 \\
\hline 1-5 Years & 9 & 9 \\
\hline 6-10 Years & 12 & 20 \\
\hline$>10$ Years & 5 & $\mathbf{6 2}$ \\
\hline Total (n) & $\mathbf{2 7}$ & 29.547 a \\
\hline Chi-square & \multicolumn{2}{|c|}{$<0.001$} \\
\hline p & \multicolumn{2}{|c|}{ Table 2a. Association between Duration of } \\
\hline
\end{tabular}

\begin{tabular}{|c|c|c|}
\hline \multirow{2}{*}{ Duration } & \multicolumn{2}{|c|}{ Hypertension } \\
\cline { 2 - 3 } & CVA & Controls \\
\hline$<1$ Years & 6 & 8 \\
\hline 1-5 Years & 17 & 29 \\
\hline 6-10 Years & 9 & 22 \\
\hline$>10$ Years & 4 & 23 \\
\hline Total (n) & $\mathbf{3 6}$ & $\mathbf{1 2 2}$ \\
\hline Chi-square & \multicolumn{2}{|c|}{$33.865^{\mathrm{a}}$} \\
\hline P & $<0.001$ \\
\hline Table 2b. Association between Duration of Diabetes \\
Mellitus and CVA \\
\hline
\end{tabular}

From this study, it is found that the $80 \%$ of CVA patients had history of prevalence of hypertension (120 patients of 150), $54 \%$ of the patients had history of prevalence of diabetes mellitus (81 patients of 150). It is also noted that $45.33 \%$ of them had history of both hypertension and type 2 diabetes mellitus. This data is depicted in Graph No. 3a and the Graph No. 3b represents the prevalence of hypertension and diabetes among control population.

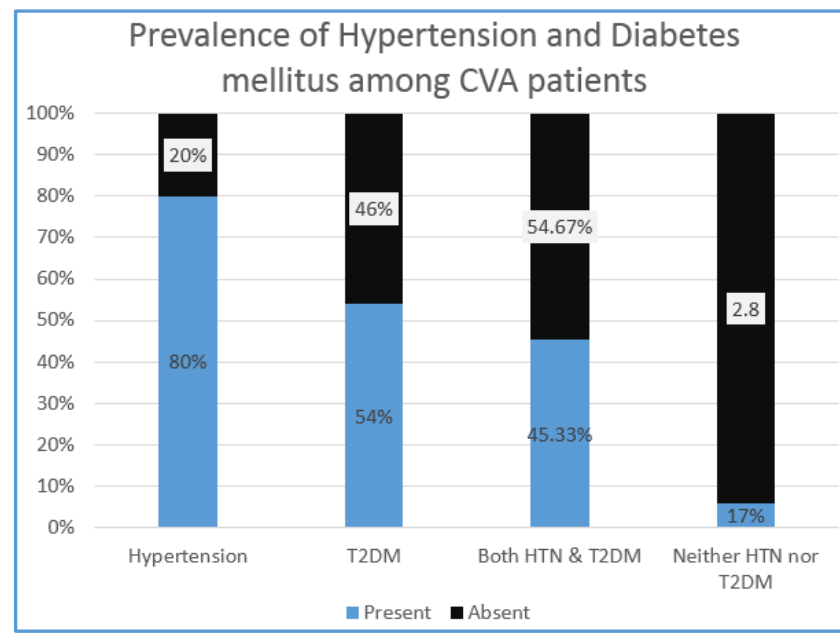

Graph 3a. Prevalence of Hypertension and $t_{2} d m$ among CVA Patients

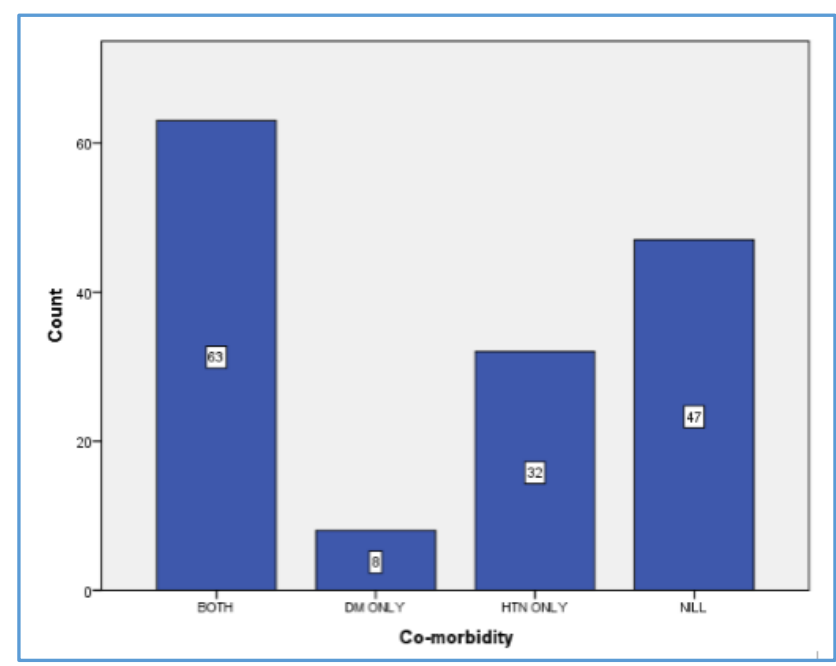

Graph 3b. Prevalence of Hypertension and T2DM among Control Population

The prevalence of hypertension and diabetes among females and males were separately considered and found that $43.3 \%$ of males and $36.6 \%$ of females had history of hypertension, $29.3 \%$ of males and $24.6 \%$ of females had 
history of type 2 diabetes mellitus. Table no. 3 depicts this prevalence of hypertension and diabetes mellitus among 150 CVA patients.

\begin{tabular}{|c|c|c|c|c|c|c|}
\hline \multirow{2}{*}{ Variables } & \multicolumn{2}{|c|}{ Males } & \multicolumn{2}{c|}{ Females } & \multicolumn{2}{c|}{ Total } \\
\cline { 2 - 7 } & No. & $\%$ & No. & $\%$ & No. & $\%$ \\
\hline Hypertension & 65 & $43.3 \%$ & 55 & $36.6 \%$ & 120 & $80 \%$ \\
\hline $\begin{array}{c}\text { Diabetes } \\
\text { Mellitus }\end{array}$ & 44 & $29.3 \%$ & 37 & $24.6 \%$ & 81 & $54 \%$ \\
\hline Both & 36 & $24 \%$ & 32 & $21.3 \%$ & 68 & $45.33 \%$ \\
\hline Table 3. Prevalence of Hypertension and t 2 dm among \\
Male and Female CVA Patients \\
\hline
\end{tabular}

\section{DISCUSSION}

From Table No. 3, it is evident that prevalence of hypertension among CVA patients is remarkably high. As per this study, $80 \%$ of the CVA patients were hypertensive that include hypertension detecting for the first time on this presentation and previously diagnosed cases. Majority of the cases had previous history of hypertension, but only a very few were under regular medication. Among this $80 \%$ and $43.3 \%$ were males and $36.6 \%$ were only females, whilst it is worth mentioning that overall incidence of CVA shows a male predominance from this study, of the 150 CVA patients 84 (56\%) were males and only 66 (44\%) were females (Graph no. 1a).

Prevalence of diabetes among CVA patients is also a significant figure, more than $50 \%$, to be exact $54 \%$ of the CVA patients were found to be diabetic. There were cases of uncontrolled diabetes and only few were on regular medication. Diabetic history of CVA patients were comparable among males and females. Among the $54 \%$ of diabetes cases, $29.3 \%$ were males and $24.6 \%$ were females.

One of the important fact that needs to be mentioned here is that even though the case control population also had hypertensive and diabetic history, almost all of them were aware about their disease status and were on regular medication for the same.

From Table No. 2 which depicts the time period since diagnosed with hypertension or diabetes, it is found that more incidences of CVA is being reported within the first five years of detecting hypertension followed by more frequency within a time period of six to ten years, but it is worth mentioning that since only a few were aware of their hypertensive status, among the 120 hypertensive CVA patients information about time period since diagnosed with hypertension was provided by only 36 patients. This result is indicative or evident of the fact that duration of being hypertensive or diabetic does not hold a direct proportionality with the incidence of hypertension, so preventive and therapeutic measures in controlling hypertension and diabetes must be taken right from the initial period to prevent the possible risk of incidence of CVA.

\section{CONCLUSION}

It is very clear that there is a high prevalence of hypertension among CVA patients and more than fifty percentage were found to have prevalence of type 2 diabetes mellitus. This study could thus very well depict the scenario prevalent among the local population of Malappuram district and these results may be indicative of the fact that uncontrolled high blood pressure increases a person's risk for stroke. Uncontrolled Diabetes mellitus also has a significant role in increasing a person's risk of stroke. So, it is advisable to take necessary steps in controlling hypertension and diabetes, and to make them aware of the early signs and symptoms of CVA. Also, it is mandatory to begin the control and preventive strategies from the initial period of diagnosing with hypertension or diabetes.

\section{REFERENCES}

[1] Walker B, Colledge NR, Ralston S, et al. Davidson's principles \& practices of medicine. 22 ${ }^{\text {nd }}$ edn. Elsevier/ Churchill Livingstone 2014; p. 1392.

[2] Roger VL, Go AS, Lloyd-Jones DM, et al. Heart disease and stroke statistics-2011 update: a report from the American Heart Association Circulation 2011;123(4):e18-e209.

[3] Abraham J, Rao PS, Inbaraj SG, et al. An epidemiological study of hemiplegia due to stroke in South India. Stroke 1970;1(6):477-81.

[4] Pandian JD, Sudhan P. Stroke epidemiology and stroke care services in India. J Stroke 2013;15(3):128-34.

[5] Anchala R, Kannuri NK, Pant H, et al. Hypertension in India: a systemic review and meta-analysis of prevalence, Awareness and control of hypertension. J Hypertension 2014;32(6):1170-7.

[6] Wild S, Roglic G, Green A, et al. Global prevalence of diabetes: estimates for the year 2000 and projections for 2030. Diabetes Care 2004;27(5):1047-53.

[7] Kaveeshwar SA, Cornwall J. The current state of diabetes mellitus in India. Australas Med J 2014;7(1):45-8.

[8] Qureshi AI, Ezzeddine MA, Nasar A, et al. Prevalence of elevated blood pressure in 563,704 adult patients with stroke presenting to the ED in the United States. Am J Emerg Med 2007;25(1):32-8.

[9] The WHO MONICA project (monitoring trends and determinants of cardiovascular disease): a major international collaboration. WHO MONICA project principal investigators. J Clin Epidemiol 1988;41(2):105-14.

[10] Prospective Studies Collaboration, Lewington S, Clarke $\mathrm{R}$, et al. Blood cholesterol and vascular mortality by age, sex and blood pressure: a meta-analysis of individual data from 61 prospective studies with 55,000 vascular deaths. Lancet 2007;370(9602):182939.

[11] American Diabetes Association. Diagnosis and classification of diabetes mellitus. Diabetes Care 2010;33(Suppl 1):S62-S9. 